\title{
Functional psychosis in childhood and adolescence
}

\author{
Sérgio K. Tengan*, Anne K. Maia*
}

\begin{abstract}
Objective: To review the literature about functional psychosis in children and adolescents, allowing pediatricians to recognize the pathology in their daily work routine.

Sources of data: Classical textbooks of child and adolescent psychiatry; search of MEDLINE and Lilacs databases (1993 to 2003). Computerized search methods were combined with manual search of the literature.

Summary of the findings: This article is structured in topics, trying to define and classify psychosis in childhood and adolescence, with schizophrenia being the main disorder. The article stresses the difficulties for the diagnosis in children, and addresses the main treatment guidelines.

Conclusion: Schizophrenia beginning in childhood, or very-early-onset schizophrenia, is a very rare pathology, almost 50-fold less frequent than early-onset schizophrenia (appearing at age 15 or later). Childhood-onset schizophrenia is a separate disorder, different from infantile autism, not only in terms of conceptual issues, but also in terms of phenomenology, genetics and associated clinical and neurological issues.
\end{abstract}

J Pediatr (Rio J). 2004;80(2 SuppI):S3-S10: Psychosis, schizophrenia, child, adolescent.

\section{Introduction}

Psychosis is a mental disorder in which a person's thoughts, affective response, and ability to recognize reality are impaired. On top of that, interpersonal relationships often are deteriorated, substantially interfering with social interactions. Typical characteristics of psychosis are: inappropriate perception of reality, delusions, hallucinations and illusions. ${ }^{1}$

It is not easy to define psychosis; therefore, sometimes we have to specify whether we are referring to the psychodynamic or psychiatric definition, or to the perspective of a given author. There are a wide series of definitions: "loss of affective contact with reality," "temporary or permanent withdrawal from objective reality," "a severe psychic disturbance that eventually

* Professor, School of Medicine, Santa Casa de Misericórdia de São Paulo. Psychiatrist, Centro de Atenção Integrada à Saúde Mental (CAISM), Irmandade da Santa Casa de Misericórdia de São Paulo (ISCM-SP), São Paulo, Brazil. leads to the deterioration of personality structures," "a pathological exacerbation of constitutional tendencies," "an extensive personality disorganization," "a severe mental disorder or pathological reactions, which vary and involve all forms of adaptation," "the final outcome of the confluence of several nociceptive factors on the psychic apparatus" or "fragmented personality."2

The existence of childhood psychoses was discussed and denied for many years, especially due to distinct definitions and different classifications that kept changing over time. ${ }^{3,4}$ The remote possibility of delusions was questioned: as children do not have a totally developed egoic structure, it was believed that they were unable to have delusions. Moreover, how could it be possible to distinguish psychotic symptoms from the "fantasy world" that is part of a child's normal development? Today, childhood psychosis is a well-known entity; but its clinical presentation in childhood differs from that observed in adults, even though we are talking about the same disease. 


\section{Classification of psychoses}

Functional psychoses differ from the so-called organic psychoses (for which there is an organic etiology) and psychogenic psychoses (clearly associated with a psychodynamic triggering mechanism). This classification takes into account the etiology of the disease, and schizophrenia is the major disorder in this group. Yet another classification divides psychoses into acute or chronic, according to the onset and duration of symptoms. 4 Here, besides time, the prognosis is also important, which is reserved for chronic psychoses.

Of note, childhood autism was considered for many years as a psychotic disorder and classified as chronic psychosis, with an extremely early onset. Still nowadays, several authors consider it a psychosis, especially those who follow a more psychoanalytic line of thought. Even in psychiatry there was and still there is a belief that childhood schizophrenia and childhood autism are the same entity, with virtually the same diagnostic criteria. ${ }^{3}$ However, the current agreement is that they are different entities, not only for theoretical reasons, but also for phenomenological, genetic, clinical and neurological aspects. ${ }^{5-7}$

Therefore, the major psychoses are classified into:

- Acute psychoses: brief psychotic disorder (reactive or psychogenic psychoses);

- Acute and recurrent psychoses (cycloid psychosis);

- Substance-induced psychotic disorder, acute organic psychoses;

- Chronic psychoses: schizophrenia;

- Schizoaffective disorder;

- Schizophreniform disorder;

- Persistent delusional disorder;

\section{Schizophrenia in children and adolescents}

Schizophrenia causes thought, perception, and emotional disorders (World Health Organization, 1992). 8 Its "classic form" (paranoid schizophrenia) includes delusions, auditory and visual hallucinations. The descriptions of these states of "insanity" are varied and are fascinating to those who study psychiatry, as well as to the population at large. These delusions show a complex organization of ideas and, if seen from a given perspective, they are understandable, although the possibility of a delusional disorder is not ruled out. Some examples of delusions are: "During the night, extraterrestrials implanted a chip in my body. Now I've been controlled 24 hours a day, every step I take is being watched by these beings and my mission is to help them." "I've been chased by drug dealers in my neighborhood, doctor! They know that I saw them dealing the drug. Now they threaten me all the time, I can't watch TV because they installed a videocamera into the TV set that controls every move in the house; even when I come here for my appointments, they know everything, because they inserted videocameras here too and they are listening to everything, they just won't leave me alone!." When schizophrenia worsens, interaction with the family and social groups becomes impossible; consequently, patients are shunned and forced by their families to seek medical care.

Schizophrenia affects approximately $1 \%$ of the population, with age at onset between 15 and 30 years. ${ }^{9}$ Early-onset schizophrenia begins before the age of 1718 years, whereas very early onset schizophrenia occurs before the age of 13 years. It is rare in childhood, but becomes more expressive at around the age of 11 . Although there are some reports of schizophrenia before the age of five years, these cases are extremely rare. ${ }^{5-}$ 10 Approximately 0.1 to $1 \%$ of cases of schizophrenia occur before the age of 10 , and approximately $4 \%$ before the age of 15 years. ${ }^{5-9}$ The disease may be underdiagnosed due to the fact that symptoms may overlap with other psychiatric diseases. Some diagnoses in childhood psychiatry are not very precise; since children are still developing, these symptoms will only become more evident in adulthood. This particularly occurs with mood disorders and psychoses. When investigating bipolar affective disorder in adults in whom the disease began in childhood, virtually half of these patients were diagnosed with schizophrenia when they were kids, that is, they were actually misdiagnosed due to the difficulty in establishing the diagnosis. $9,11,12$

The diagnostic criteria used are an obstacle to the diagnosis of schizophrenia. The World Health Organization ${ }^{8}$ and the American Association of Pediatrics ${ }^{13}$ use the same diagnostic criteria for children and adults. The use of the same criteria for different ages has been criticized. Firstly because childhoodonset schizophrenia is considered to be different from the adult form; as children's psychic and cognitive structures are not fully developed, how come delusions could occur? ${ }^{6}$ Secondly, for the presence of hallucinations or delusions: if present, how could they be confirmed, once these accounts may be part of a child's "fantasy world"? In fact, studies on childhood-onset psychoses show that hallucinations and delusions are observed with the same frequency as in adults; however, its expression is different from that seen in adults as a result of cognitive characteristics of different age groups. ${ }^{5,14}$ Other studies also reveal that the use of the same criteria for the diagnosis of schizophrenia in childhood has a high predictive value, suggesting continuity of symptoms into adulthood.11

\section{Etiology of schizophrenia \\ Genetic and neurobiological aspects}

The genetic transmission of mental disorders includes the distinction between congenital and environmental factors involved in the etiology of these disorders. Such 
distinction is difficult in adults, let alone in children: what should be the percentage of disease attributed to genetic, congenital and structural factors? And what should be the percentage attributed to environmental factors, family stress, maltreatment, or deficient mother-baby relationship? Obviously, these questions cannot be precisely answered. Each school of thought, each period of childhood psychopathology has given answers that follow the current tendency.

The term childhood psychosis or psychoses is another complication of childhood psychiatry: does it include or not autism and global developmental disorders? Current data and investigations in psychopathology and nosography of mental disorders in children show a clear distinction between pervasive developmental disorders, observed right from the beginning (if not explicit, at least latent), and psychotic disorders, which as with adults, represent a change in previous functioning. 15

The present study is concerned with psychotic disorders, pervasive developmental disorders (PDD) and global developmental disorders (GDD), which includes autism. In other words, autism is not discussed herein. However, some genetic aspects of autism are addressed.15-17

A heated discussion between the organicist and psychoanalytic, or perhaps psychodynamic schools of thought has taken place in the last decades. Where did so peculiar and severe symptoms of these contemplative and estranged children come from? From a physiological incapacity of the brain to communicate, or from a psychological rejection, an active refusal to contact with others? ${ }^{15}$ From hardware or software? This discussion has lost sense in the last few years, since an undeniably genetic etiology has been implicated. Actually, the pattern of genetic inheritance is what has been confirmed, because the etiology will only be determined when the chromosome and the gene(s) involved are accurately located. We may affirm that the etiology is NOT psychological, even if the course, pathogeny and presentation are unique and "caused" by the psychological environment. ${ }^{16}$

A study carried out by Brazilian psychiatrist Mônica Zilbovicius with a group of 21 autistic children showed a "well-defined hypoperfusion in the superior temporal gyrus and in the superior temporal sulcus."17

In schizophrenia, biological factors are primary and psychosocial factors play an essential role. 5,6 The genetic component has been confirmed by family studies, adoption studies and twin studies. Today, improved molecular biology techniques map the genes that make individuals susceptible to schizophrenia. ${ }^{18}$

Prenatal and perinatal risk factors for schizophrenia are investigated in an attempt to identify brain involvement in neurodevelopment. Pregnancy and childbirth complications, prenatal exposure to viral infections, neuropathological findings such as abnormal cytoarchitecture ${ }^{5,18}$ are provably associated with higher risk for schizophrenia. Thus, adult schizophrenic patients consistently show reduced brain volume, enlarged lateral ventricles, in addition to the smaller size of the temporal lobe in the hippocampal region. Histopathological findings suggest dysgenesis instead of degeneration, such as lower number of cortical and periventricular neurons, absence of glial cells, change in the position of pyramidal cells. 18

With regard to neurochemistry, the dopaminergic hypothesis is the main theory, since most neuroleptics or antipsychotics are dopamine blockers; ${ }^{7}$ this theory suggests an increase in the activity of the mesolimbic dopaminergic system, which is important for modulating acquisition, motivation, and emotion.

Besides dopamine, other biogenic substances are probably involved: norepinephrine, serotonin, and other neurotransmitter neuropeptides; neuroimaging studies with PET and SPECT reveal neurotransmitter receptors in different brain regions, in addition to confirming D2 receptor blockade by neuroleptics (maybe D4 with clozapine). ${ }^{7}$

The neurodevelopment approach has been widely studied, involving at least two aspects: ${ }^{19}$ normal development at the beginning, submitted to injury in the most critical developmental period (perinatal trauma, congenital viral infection), changing the cytoarchitecture; or development with abnormal onset, not apparent in the first years, and perceived during maturation by some stressor. This second hypothesis explains that, among individuals submitted to the same pathogenic conditions, only individuals with higher vulnerability will develop schizophrenia.

Biochemical studies ${ }^{19}$ in children with schizophrenia are rare and inconclusive. For instance, the comparison of serum levels of immunoreactive beta-endorphin in autistic, schizophrenic and healthy children does not show any changes in children with untreated schizophrenia, but shows an increase in beta-endorphin levels in association with neuroleptic administration. ${ }^{19}$ Another study compared the metabolism of catecholamine and plasma dopamine-beta-hydroxylase and found a significant difference in the subgroup of patients with schizophrenia- low level of pDBH. ${ }^{19}$

The neurobiology of childhood-onset schizophrenia should be further investigated, 5,6 in order to improve the definition of and knowledge about the disease and to improve therapeutic approach and prognosis.

\section{Diagnosis and clinical course}

The diagnostic criteria used for schizophrenia by the American Association of Psychiatry (DSM-IV, 1994) 13 and by the World Health Organization International Classification of Diseases (ICD-10, 1992) ${ }^{8}$ are quite similar and show equivalent symptoms for childhoodonset schizophrenia. Table 1 shows the DSM-IV diagnostic criteria for schizophrenia. Two of the following symptoms 
are necessary for the diagnosis: delusions, hallucinations (positive symptoms), disorganized speech, roughly disorganized or catatonic behavior or negative symptoms (remarkable apathy, poor speech, blunting of affect or incompatibility of emotional responses, social withdrawal). These initial symptoms last for at least one month, or less if successfully treated. One should recall

Table 1 - DSM-IV diagnostic criteria for schizophrenia

A. Characteristic symptoms: Two (or more) of the following, each present for a significant portion of time during a 1-month period (or less if successfully treated):

- delusions

- hallucinations

- disorganized speech (e.g., frequent derailment or incoherence)

- grossly disorganized or catatonic behavior

- negative symptoms, i.e., affective flattening, alogia, or avolition

Note: Only one Criterion A symptom is required if delusions are bizarre or hallucinations consist of a voice keeping up a running commentary on the person's behavior or thoughts, or two or more voices conversing with each other.

B. Social/occupational dysfunction: For a significant portion of the time since the onset of the disturbance, one or more major areas of functioning such as work, interpersonal relations, or self-care are markedly below the level achieved prior to the onset (or when the onset is in childhood or adolescence, failure to achieve expected level of interpersonal, academic, or occupational achievement).

C. Duration: Continuous signs of the disturbance persist for at least 6 months. This 6 -month period must include at least 1 month of symptoms (or less if successfully treated) that meet Criterion A (i.e., active-phase symptoms) and may include periods of prodromal or residual symptoms. During these prodromal or residual periods, the signs of the disturbance may be manifested by only negative symptoms or two or more symptoms listed in Criterion A present in an attenuated form (e.g., odd beliefs, unusual perceptual experiences).

D. Schizoaffective and mood disorder exclusion: Schizoaffective disorder and mood disorder with psychotic features have been ruled out because either (1) no major depressive, manic, or mixed episodes have occurred concurrently with the active-phase symptoms; or (2) if mood episodes have occurred during active-phase symptoms, their total duration has been brief relative to the duration of the active and residual periods.

E. Substance/general medical condition exclusion: The disturbance is not due to the direct physiological effects of a substance (e.g., a drug of abuse, a medication) or a general medical condition.

F. Relationship to a pervasive developmental disorder: If there is a history of autistic disorder or another pervasive developmental disorder, the additional diagnosis of schizophrenia is made only if prominent delusions or hallucinations are also present for at least a month (or less if successfully treated). that the diagnosis is evolutional, requiring at least six months of disease, including the active phase.

\section{Schizophrenia subtypes}

Schizophrenia can be subdivided into five types according to predominant symptoms at the time of assessment: paranoid, disorganized or hebephrenic, catatonic, undifferentiated or simple, and residual.8,13 Paranoid schizophrenia is the most common type; its clinical course includes delusions and hallucinations, in addition to affective disorder and pragmatism. In the disorganized or hebephrenic type, the major characteristic is thought disorder, incoherent speech, and illogical combination of ideas; the prognosis is poor, especially due to the quick development of negative symptoms such as blunting of affect and avolition. The catatonic type is characterized by prominent psychomotor symptoms that may alternate, such as hyperkinesis, stupor or automatic obedience and negativism. Forced attitudes and postures may be maintained for long periods, and episodes of extreme agitation may occur. For unknown reasons, this type of schizophrenia has been seldom observed nowadays. The undifferentiated type is not easily characterized; symptoms meet the criteria for schizophrenia, but do not meet the criteria for the paranoid, disorganized or catatonic type. Quite often, this type of schizophrenia is mistaken for a personality disorder. The residual type is the chronic form of the disease, where there is a clear progression of psychotic symptoms of schizophrenia; however, at this late stage, negative symptoms prevail.

\section{Peculiarities of childhood schizophrenia}

Childhood-onset schizophrenia has some peculiarities compared to adult-onset schizophrenia. When its onset occurs before the age of 12 years it is strongly associated with behavioral problems. Children have been described as socially maladapted, weird or withdrawn, in addition to having behavioral disorders and delayed psychomotor development. 5,9,11 Although many children have this symptom or complaint, these symptoms are not diagnostic of the disease and should not be used as parameters for the diagnosis of schizophrenia. Despite the fact that we do not talk about personality at this stage of life, these symptoms are relevant and seem to be precursors of childhood schizophrenia, being a continuum of the negative symptoms of the disease. ${ }^{11}$ Retrospective studies of patients with adult-onset schizophrenia have shown a similar psychological profile, in addition to the abuse of psychoactive substances. ${ }^{20}$

\section{Productive symptoms}

In childhood-onset schizophrenia, thought disorders, especially disorganized ideas, delusions, hallucinations, and poor affective resonance are frequently observed. 
The presence of such symptoms seems not to change with age, but their expression varies with age, being more complex with the advance of age. $5,6,9$

\section{Insidious onset}

Childhood-onset schizophrenia usually has an insidious onset, which often is difficult to define. 6,9 The symptoms usually persist for one year before being diagnosed, which may be detrimental to the child and family because of late diagnosis.

\section{Male preponderance}

Male preponderance is the major difference between childhood-onset schizophrenia and adult-onset schizophrenia. 5, 6 While the proportion of men and women is virtually the same in the adult population, boys are affected twice as much as girls in the pediatric population. Several studies have shown differences as to the course of the disease between genders. Schizophrenia often develops earlier in men than in women, with a more intense cognitive involvement, and a worse outcome, in addition to a poor response to neuroleptics. 6,21

\section{Cognition and language}

Mental deterioration in patients with schizophrenia is almost inevitable. 22 Approximately 10 to $20 \%$ of schizophrenic children have a decrease in their intelligence quotient. 9,11,22 Mental deterioration is significantly more pronounced than in nonschizophrenic psychoses. ${ }^{11}$ In addition to cognitive deficit, attention deficit, learning disabilities and abstraction are also observed. ${ }^{23}$ With the advent of modern therapeutic modalities, these symptoms can be minimized, but treatment is essential for these patients. ${ }^{21}$

Communication problems are frequent and require that thoughts and the presence of hallucinations be carefully assessed, since they may be mistaken for language disorders. In these cases, observing the child's behavior is crucial. Mental deterioration and the deterioration of global functioning are visible in psychotic children. ${ }^{9}$

\section{Secondary enuresis}

Its incidence is higher in pediatric patients, without a physiological cause, and may considered a negative symptom of psychosis. ${ }^{11}$

\section{Differential diagnosis}

When the diagnosis of schizophrenia is suspected, one should bear some aspects in mind. The first one is age at onset, recalling that schizophrenia has an evolutional course and has an apparently normal previous history. Its onset is extremely rare before the age of seven years. Family history is also important, since other affected individuals are usually encountered. It is not a simple diagnosis and it might be difficult to distinguish it from other disorders, especially from bipolar affective disorder, therefore requiring reassessments on a regular basis.

\section{Mood disorders}

Bipolar affective disorder in children often has a similar presentation to childhood psychoses. Manic-depressive illness often is characterized by delusions and hallucinations, which is misleading in terms of diagnosis. Approximately half of patients with adolescent-onset bipolar disorder were misdiagnosed with schizophrenia in the past, thus hindering diagnosis during childhood and adolescence. $6,9,12$ After treating the manic-depressive illness with drugs, symptoms tend to subside, and seemingly, no "defect" is observed after this episode. In schizophrenia, individuals tend to present impaired social interactions and avolition (negative symptoms) after the psychosis. ${ }^{21}$

\section{Global developmental disorder (Childhood autism/ Asperger's syndrome)}

Childhood autism is different from childhood-onset schizophrenia, not only in its definition, but also with regard to phenomenological, genetic, biological and neurological aspects. ${ }^{5}$ Diagnosis often is established around the third year of life, although it may be established before this age. In general, it is not difficult to distinguish between these two entities, since in schizophrenia children do not have the speech disorders that are observed in autism, such as lack of speech or speech with no communication. ${ }^{7}$ Perhaps, the major difficulty in differential diagnosis concerns autistic adolescents with better functioning or with Asperger's syndrome (in these cases, cognition is not so compromised), and the presence of language and the thought process may be mistaken for delusions. However, other symptoms observed in patients with autism from the very first years of life distinguish it from schizophrenia. 6,7,9

\section{Organic symptoms}

It is extremely important that functional psychoses be distinguished from organic ones, and that a thorough investigation of possible causes be carried out, including a detailed clinical history and physical examination, and laboratory and imaging exams. Delirium (which is different from delusion) is an acute confusional state, characterized by attention deficit, confusion, variations in the state of mind throughout the day, often with hallucinations, illusions and sometimes episodes of psychomotor agitation. In general, the onset is acute, and often is mistaken for psychotic disorder after being established. The causes of delirium are varied, and require extensive clinical investigation. In a significant number of cases, the causative factor is not determined, but an organic etiology is not ruled out. ${ }^{24}$ It is a severe condition, and it may result in death, sometimes. After 
the cause is treated, remission occurs, and patients may return to normal or present with cognitive deficit or other sequelae. The causes of delirium include postictal confusion states in epilepsies, central nervous system injury (tumors, traumas, malformations, etc.), degenerative diseases (Huntington's disease, lipid storage diseases), metabolic disorders (endocrine diseases, Wilson's disease), toxic (abuse of amphetamines, cocaine, hallucinogens, phencyclidine, solvents), in addition to medications such as corticosteroids, anticholinergics and heavy metal poisoning. Infectious diseases such as meningitis, encephalitis, and AIDS should also be ruled out. ${ }^{9}$ Dementia in childhood, which could be mistaken for schizophrenia, is extremely rare; and when it occurs, it is accompanied by remarkable intellectual decline and abnormal neurological findings. ${ }^{9}$

\section{Behavioral disorders, emotional and dissociative disorders}

Children with severe behavioral or emotional problems sometimes have attitudes that seem inappropriate or even bizarre, described as "psychotic symptoms." Differently from childhood psychoses, no delusions or hallucinations are observed. Usually, children's behavior is associated with serious emotional problems, which require careful psychodynamic investigation, sometimes involving child abuse or negligence. The approach in these cases often demands that health professionals take actions to protect children.

\section{Communication disorders}

Children with speech and language disorders seem to have thought disorders, which may be mistaken for psychotic disorders. Careful evaluation shows no thought disorders or absence of other psychotic symptoms such as delusions and hallucinations. ${ }^{9}$ Other factors that often are misleading concern associated behavioral disorders.

\section{Other psychoses}

Childhood schizophrenia is different from other psychoses as it is more chronic and compromises intellectual functions and several other functions. In general, reactive or psychogenic psychoses have a very favorable and rapid response to medication. A stressor is easily observed in these children. Reactive psychoses have been described at a higher frequency in developing countries or in immigrants where external factors favor the development of psychosis. 6

\section{Other disorders}

Personality disorders are diagnostic entities that are almost always used only in the adult population, since children are still in the process of developing and therefore their personality structures are not fully formed yet. However, some personality disorders, such as antisocial personality disorder, should include a history of conduct disorder before the age of 15 years. Actually, personality disorders apparently begin in childhood and continue into adulthood, being a continuum of the same disease. 27 Under these aspects, borderline schizoid, schizotypal and paranoid "personality disorders" are important for the differential diagnosis of childhood schizophrenia. 9,27

\section{Course and prognosis}

The course of schizophrenia varies and is influenced by several factors, such as age at onset, type of schizophrenia, gender, in addition to individual and environmental factors that might interfere with its prognosis. ${ }^{6-21}$ The course of the disease often oscillates, initially having a prodromal phase, followed by an active phase, with crises and various symptoms, when diagnosis is usually established. With the progression of the disease, episodes of crisis, recovery, and residual phase are observed. In schizophrenia, individuals do not return to their previous state after stabilization of the crisis; usually, their affect and pragmatism are impaired: the so-called post-crisis "defect". The prognosis of the disease is reserved, despite the fact that the new pharmacological therapies have improved its prognosis. Factors that indicate a better prognosis are: late onset, clearly defined triggering factor, acute onset, favorable social history such as a job or interpersonal relationships, presence of depressive symptoms, being married (which clearly does not apply here), positive symptoms (delusions and hallucinations) and favorable family and social support. Factors that indicate a worse prognosis are: early onset, absence of triggering factors, premorbid factors such as poor social adaptation (including work), autistic behavior, negative symptoms, poor family and social support, non-remission within three years, frequent relapses. ${ }^{21}$ Childhood schizophrenia often has a worse prognosis mainly due to its early onset and to the preponderance of negative symptoms. $6,9,21$

\section{Additional exams}

Additional exams for the diagnosis of schizophrenia are not necessary, except to rule out the possibility of an organic cause. The diagnosis is basically clinical, according to symptoms and progression. Imaging studies do not have a diagnostic importance, but they help elucidate the brain structures involved in the disease. Cranial computed tomography has revealed ventricular dilatation as a result from the reduction of brain parenchyma in some patients. 25,26 The same findings have been reported in children, showing the involvement and severity of affected brain areas. ${ }^{26}$ Magnetic resonance has shown differences in the volume of the temporal and parietal lobes in adults with schizophrenia, especially reduction in the anterior portion of the 
amygdala-hippocampus portion, being more pronounced on the left side. These findings are not present in children; they begin to appear in adolescence. 26

\section{Treatment}

The treatment of psychoses consists of pharmacotherapy and socio-educational approach. Drug therapy includes neuroleptics or antipsychotics. The efficacy of these drugs in treating psychoses has been demonstrated in many studies. Unfortunately, studies of these drugs in children are infinitely less common than in adults. For many reasons, studies on neuroleptics are initially made with adult patients, and only after some years, these drugs are released for use in children. A large number of (atypical) neuroleptics have been released in the last few years with proven efficacy and fewer adverse effects, but their use in the treatment of childhood psychoses is still restricted. Haloperidol, a drug that has been used for several years now, still is a good choice for the treatment of childhood psychoses (dose of 0.02 to $0.12 \mathrm{mg} / \mathrm{kg} /$ day). ${ }^{9}$ Although it has side effects, such as extrapyramidal symptoms and akathisia, these effects are easily controlled, and it is an extremely safe drug. Another good option is risperidone, which has a risk for tardive dyskinesia that is far lower than that of haloperidol. Olanzapine has been used in the treatment of childhood psychoses and shown a good response. ${ }^{9}$

\section{Psychosocial approach}

Not enough information is available in the literature to support that certain psychotherapeutic techniques are efficient in treating childhood schizophrenia. ${ }^{9}$ It seems that socio-educational actions directed towards family functioning, problem solving, and communication skills have been more effective in reducing the number of crises. In our setting, the treatment of these cases at day-hospitals has shown a better outcome. Usually, the child is admitted to a day-hospital for about two to five times a week, during half of the day, where he/she is assisted by a multidisciplinary team. The family also participates in some activities, which include education on the disease and on dynamic factors that might interfere with it.

\section{Family guidance and family therapy}

An ill child in a family almost always disrupts family relationships, especially when a mental disease is present. Quite often, diseased individuals show different feelings, such as guilt, anger, fear, shame, failure, among others. In some situations, family guidance may solve the problem. However, in families in which relationships are already problematic, an ill child only adds to the existing problems, where the child does not have an opportunity for changes, and then it is necessary that family therapy be implemented as a way to improve understanding of the conflicts and to seek a solution to them. ${ }^{28}$

\section{References}

1. Sadock BJ. Signs and Symptoms in Psychiatry. In: Sadock BJ, Sadock VA, editors. Comprehensive Textbook of Psychiatry. 7th ed. Baltimore: Lippincott Williams \& Wilkins; 2000. p. 677-89.

2. Assumpção FB. Psicoses: Crítica dos Conceitos. Revista de Neuropsiquiatria da Infância e Adolescência. 1993;1(2):13-18.

3. Ajuriaguerra J, Marcelli D. Psicoses infantis. In: Ajuriaguerra J, Marcelli D. Manual de Psicopatologia Infantil. 2nd ed. Porto Alegre: Artes Médicas; 1991. p. 240-267.

4. Krynski S, Assumpção FB. Nota sobre o conceito e classificação das psicoses na infância. Bol CEEP. 1987;5:20-3.

5. McKenna K, Gordon CT, Rapoport JL. Childhood - onset schizophrenia: timely neurobiological research. J Am Acad Child Adolesc Psychiatry. 1994;33(6):771-81.

6. Werry JS, Taylor E. Schizophrenia and allied disorder. In: Rutter M, Taylor E, Hersov L, editors. Child and Adolescent Psychiatry. 3rd ed. Oxford: Blackwell Science; 1994. p. 594-615.

7. Lord C, Rutter M. Autism and pervasive developmental disorders. In: Rutter M, Taylor E, Hersov L, editors. Child and Adolescent Psychiatry. 3rd ed. Oxford: Blackwell Science; 1994. p. 569-93.

8. Classificação de Transtorno Mental e de Comportamento da CID-10; Descrições clínicas e diretrizes diagnósticas - Coord. Organização Mundial da Saúde. Trad. Dorgival Caetano - Porto Alegre: Artes Médicas; 1993. p. 83-107.

9. McClellan JM. Early-onset schizophrenia. In: Sadock BJ, Sadock VA, editors. Comprehensive Textbook of Psychiatry. 7th ed. Baltimore: Lippincott Williams \& Wilkins; 2000. p. 2782-2789.

10. Hollis C. Adult outcomes of child and adolescent onset schizophrenia: diagnostic stability and predictive validity. Am J Psychiatry. 2000;157:1652-9.

11. Hollis C. Developmental precursors of child and adolescent onset schizophrenia and affective psychoses: diagnostic specificity and continuity with symptom dimension. $\mathrm{Br}$ J Psychiatry. 2003;182:37-44.

12. Lee FI. Epidemiologia e fatores clínicos dos transtornos afetivos na infância e adolescência. In: Assumpção FB, editor. Transtornos Afetivos na Infância e Adolescência. São Paulo: Lemos Editorial; 1996. p. 19-31.

13. Critérios diagnósticos do DSM-IV; referência rápida. 4th ed. Porto Alegre: Artes Médicas; 1995. p. 141-153.

14. Makowski D, Waternaux C, Lajonchere CM, Dicker R, Smoke N, Koplewicz $H$, et al. Thought disorder in adolescent-onset schizophrenia. Schizophr Res. 1997;23:147-65.

15. Mazet P, Lebovici S. Autisme et psychoses de I'enfant. P.U.F. Presses Universitaires de France; 1990.

16. Frith U. Autism and Asperger Syndrome. Cambridge: Cambridge University Press; 1997.

17. Chardavoigne A. Autisme: décodage en progrès. Science et Vie. 2003:71-75.

18. Shirakawa I, Chaves AC, Maria JJ. O Desafio da Esquizofrenia. São Paulo: Lemos Editorial; 1998. p. 33-66.

19. Campbell M, Spencer EK, Kowalik SC, Erlenmeyer-Kimling L. Schizophrenic and psychotic disorders. In: Wiener JM, editor. Textbook of Child and Adolescent Psychiatry. Washington, DC: American Psychiatric Press; 1991. p. 221-239.

20. Amminger $P$, Pape $S$, Rock $D$, Roberts $S A$, Ott $S L$, SquiresWheeler $\mathrm{E}$, et al. Relationship between childhood behavioral disturbance and schizophrenia in New York high-risk project. Am J Psychiatry. 1999;156:525-30.

21. Cancro R, Lehmann H. Schizophrenia - clinical feature. In: Sadock BJ, Sadock VA, editors. Comprehensive Textbook of Psychiatry. 7th ed. Baltimore: Lippincott Williams \& Wilkins; 2000. p. 1169-1199.

22. Kremen WS, Buka SL, Seidman LJ, Goldstein JM, Koren D, Tsuang TT. IQ Decline during childhood and adult psychotic symptoms in a community sample: a 19-year longitudinal study. Am J Psychiatry. 1998;155:672-7.

23. Kunra S, Wiggs E, Bedwell J, Smith AK, Arling E, Albus K, et al. Neuropsychological deficits in pediatric patients with childhoodonset schizophrenia and psychotic disorder not otherwise specified. Schizophr Res. 2000;42:135-44.

24. Caine E, Lyness JM. Delirium, dementia, and amnestic and other cognitive disorders. In: Sadock BJ, Sadock VA, editors. Comprehensive Textbook of Psychiatry. 7th ed. Lippincott Williams \& Wilkins; 2000. p. 854-923. 
25. Gur RE, Gur RC. Schizophrenia: brain structure and function. In: Sadock BJ, Sadock VA, editors. Comprehensive Textbook of Psychiatry. 7th ed. Baltimore: Lippincott Williams \& Wilkins; 2000. p. $1117-1129$

26. Kumra S, Giedd JN, Vaituzis AC, Jacobsen LK, McKenna K, Bedwell J, et al. Childhood-onset psychotic disorders: magnetic resonance imaging of volumetric differences in brain structure. Am J Psychiatry. 2000;157:1467-74.

27. Hill J, Rutter M. Personality disorder. In: Rutter M, Taylor E, Hersov L, editors. Child and Adolescent Psychiatry. 3rd ed. Oxford: Blackwell Science; 1994. p. 688-696.
28. Oliveira BSA, Pedrozo CAZP, Macedo HO. Como receber pacientes em uma clínica escola de fonoaudiologia: uma nova proposta. In: Lagrotta MGM, César CPHAR. A Fonoaudiologia nas Instituições. São Paulo: Editora Lovise; 1997. p. 55-60.

Corresponding author:

Sérgio K. Tengan

Rua Major Maragliano, 241

CEP 04017-030 - São Paulo, SP, Brazil

Tel.: +55 (11) 5087.7039

E-mail: infancia.caism@ig.com.br 